\title{
Perceptions of Good and Bad Leaders by Teachers in Pakistan
}

\author{
Dr Mona Aeysha Khalid \\ Assistant Prof. of Education \\ Panasastra University of Cambodia, Kingdom of Cambodia \\ Tariq Mahmood \\ PhD Research Fellow \\ University of Education, Division of Education, Lahore, Pakistan \\ Corresponding author:+923014981592, tariq_903@hotmail.com \\ Abdur Rasheed Shah \\ PhD Research Fellow \\ University of Education, Division of Education, Lahore, Pakistan
}

\section{Doi:10.5901/mjss.2013.v4n2p543}

\section{Abstract}

\begin{abstract}
Leadership have multiple directions through that directions we can view leadership Fielder (1967), Keith (1977), Bowers and Seashore (1966). Pakistan's overall political and regional instability since the day of independence (1947) is partly due to poor leadership skills and overall weak structure of leadership. One may easily visualize that qualities of an organization could not be achieved unless leaders are vigilant, intelligent, hardworking, goal oriented, persistent, determined, and highly motivated to establish a strong sense of teamwork with great vision, while having good and healthy relationships with their employees, being conscious of high moral values and ethical standards. This research paper will identify the strongly emphasized traits of leaders demanded by the young generation of Pakistan and will identify the weak or negative traits that are either nonessential for a leader or the least important ones especially at present stage.
\end{abstract}

Key words: leadership, perception, traits of leaders, teachers.

\section{Introduction}

Leadership can be viewed as a status group, a focal person, a function, or a process. Heads of departments, directors, principals, administrators, managers, bosses, and executives may all be included in the category of focal persons of leadership. The focus of much of the research has been on the personality traits and behaviors of leaders. Some argue that leadership is a dynamic process in which leader - follower relationships develop through interpersonal communication skills. However the emphasis in our society may be seen on leader attributes and actions.

Leadership can be defined in many ways. Fielder (1967) cites many definitions and emphasizes coordinating task oriented group activities. This approach seems to indicate that leading is synonymous with managing. As Keith (1977) has described it, "Leadership is the ability to persuade others to seek defined objectives enthusiastically. It is the human factor that binds a group together and motivates it toward goals."

The study of educational leadership has also gained much importance in recent years with the Ohio State studies of Stodgill (1951), although culturalperceptions of leadership have not been analyzed thoroughly and very little research has been carried out in developing countries, especially in Pakistan, to relate perceptions of leadership with desired attributes in leaders.

Among the many approaches towards leadership of change, the trait approach emphasized the personality characteristics, value systems, and life styles of leaders. Thus research revolving around such an approach usually considered the traits of established leaders. Such lists could be unlimited but usually included traits like energy, hard work, intelligence, direction, purpose, enthusiasm, friendliness, integrity, morality, expertise, decisiveness, perceptions, 
knowledge, wisdom, determination, persistence, endurance, good looks, intelligence, courage, and personality with high aims. There is little agreement with regard to which trait should be included and which should not be. In fact, there is clear cut disagreement with regard to which of such traits are most important to a successful leader. The danger attached with such an approach is mentioned by Solomon (1950), who states that the attributes are desirable but their presence may not be prerequisite. So the trait approach basically explains what a leader is rather what a leader should be, and includes what is related to different leadership styles like authoritarian, democratic, and laissez-faire (Fremont and James, 1986).

On the other hand, a major focus in leadership research has been to identify specific behaviors that contribute to effective leadership styles. According to Bowers and Seashore (1966) there are four dimensions: support, interaction facilitation, goal emphasis, and work facilitation. Support and interaction basically encourage team work in organizations. The other two: goal emphasis and work facilitation are basically task oriented and related to goal theory of leadership. Some people are more task oriented while others focus only on relationship. It would be more realistic to maintain the balance between the two types according to the particular situation.

Sergiovanni's (2001) ideas on good leadership focus on a more visionary or motivated type within the leadership debate. He uses language like, "Leadership that counts is far more cognitive than it is personality based or rules based. Cognitive leadership has more to do with purposes, values, and frameworks that oblige us morally than it does with needs that touch us psychologically or with bureaucratic things that push us organizationally".

Gunter's (2001) recommendations in this regard are very realistic and suitable. She focuses on relatively different types of educational leadership in which what we need is less emphasis on restructuring hierarchical leadership and more courage to enable teachers and students with managers to work on developing learning processes.

Zaleznik (2004) and Kotter (1991) indicated that leadership is more of delivering change, developing a vision and direction, whereas management is primarily related to concepts like organizing, planning, budgeting, and control. In their papers the focus is heavily on the actions of heads or principals as the formally constituted leaders in any educational set up. As Bottery (1994) has recommended, an essential function of a leader is to present pupils and teachers with their own personal vision of where the college and society will be directed, while another is to provide a base to discuss or debate over other visions. Thus it is greatly needed to have schools with broader visions, quite a different leadership style from styles needed in other organizations, and such needs must be based on the evaluation of their own employees and colleagues.

According to Adair (1973) a leader must be enriched by qualities like enthusiasm, confidence, toughness, integrity, warmth, and humility. Similarly for a good leadership, many behavioral characteristics are required. A survey named as " the Industrial Survey" revealed that a leader must show enthusiasm, support other people, recognize individual efforts, listen to individual ideas, provide direction, have personal integrity, practice what he or she preaches, encourage team work and feed back, and develop other people ( Michael and Tina, 2006).

We cannot bring a change in an organization until we hold the same principles we expect others to follow. A leader must first set an example of him and then set the same criterion for others. Principle-centered people are constantly educating themselves by their experiences, trainings, queries, learning new skills, and discovering new ideas, and in this way they continually expand their competencies. They are very much service oriented, enthusiastic and optimistic people. At the same time they believe in other people and lead a balanced life. They see life as adventure as they will discover new territories and make new contributions. Their security lies in their initiative, creativity, courage and native intelligence. They are synergistic and catalysts for change. In team work they use their strengths and strive to complement their weaknesses with the strengths of others. They regularly exercise to improve their physical, mental, emotional, and spiritual states; especially they indulge themselves in exercising their minds through reading, creative problem solving, writing and visualizing (Stephen, 1997). Indeed, we need this kind of leaders in our society.

In effect, effective leaders do a lot behind the scenes of work and realize that formal communication and decision making are not enough; rather, effectiveness comes from numerous networking interactions of short duration while covering many areas supporting a well organized agenda (Barker, 2007). One may easily assess that such qualities of an organization could not be achieved unless leaders are vigilant, intelligent, hardworking, goal oriented, persistent, determined, and highly motivated to establish a strong sense of teamwork with great vision, while having good and healthy relationships with their employees, being conscious of high moral values and ethical standards.

A survey type study was conducted to analyze the present situation. 100 Pakistani teachers were asked to fill out a questionnaire concerning their perceptions of the traits and behaviors of good leaders and bad leaders. The teachers were randomly drawn from several schools and colleges from Punjab Province of Pakistan. For the purpose of data collection one the questionnaire was developed comprising of four parts i.e. (I) eight choices for traits of good leaders (II) eight choices for behavior of good leaders (III) eight choices for traits of bad leaders (IV) eight choices for behaviors of 
bad leaders. The questionnaire was given to 100 school/college teachers in the Punjab region of Pakistan.

The teachers were asked to think of a person they considered an excellent leader, and to rank the top three leadership traits that contributed to that person's great leadership. For the same purpose, they were also asked to rank the top three behavior characteristics that contributed to that person's outstanding leadership. On the other hand the teachers were asked to think of a person whom they knew as a bad leader and to rank the top three qualities of both personality and behavior that contributed to that person's bad leadership. Here it is important to note that most of the respondents were confused to rank traits of good leaders as they could not decide whether they should mention actual traits of their previous leaders in order or the traits they prefer to see in their leaders. Then the question was modified accordingly as 99 percent were more comfortable in organizing the traits they wished their leaders had. They were also ready to rank negative traits of their leaders accordingly.

Analysis of the results was conducted in two phases. First choices of respondents were tabulated to see which aspects of behavior and character were mentioned most often, which were neglected as a whole, and which were given medium priority. In the second phase each trait or behavior was given a score depending on the rankings of the teachers: a first choice was given 3 points, a second choice was given 2 points, a third choice was awarded 1 point. In this way, a mean score was calculated for each trait and behavior. The various traits and behaviors could then be compared as to which ones had higher mean scores than others.

\section{Discussion of Results}

Table \# 1: Percentage response about character traits of good leaders

\begin{tabular}{lcccc}
\hline Character traits & Choice I & Choice II & Choice III & Mean Value \\
\hline Intelligent & 40.0 & 7.0 & 4.0 & 1.38 \\
good public speaker & 9.0 & 12.0 & 10.0 & .61 \\
dependable and consistent & 6.0 & 14.0 & 9.0 & .55 \\
Broad vision shared & 7.0 & 15.0 & 16.0 & .67 \\
Friendly personality & 9.0 & 17.0 & 16.0 & .77 \\
honest and trust worthy & 16.0 & 9.0 & 13.0 & .79 \\
self confident & 7.0 & 12.0 & 16.0 & .61 \\
persistence in achieving goals & 6.0 & 14.0 & 16.0 & .62 \\
\hline
\end{tabular}

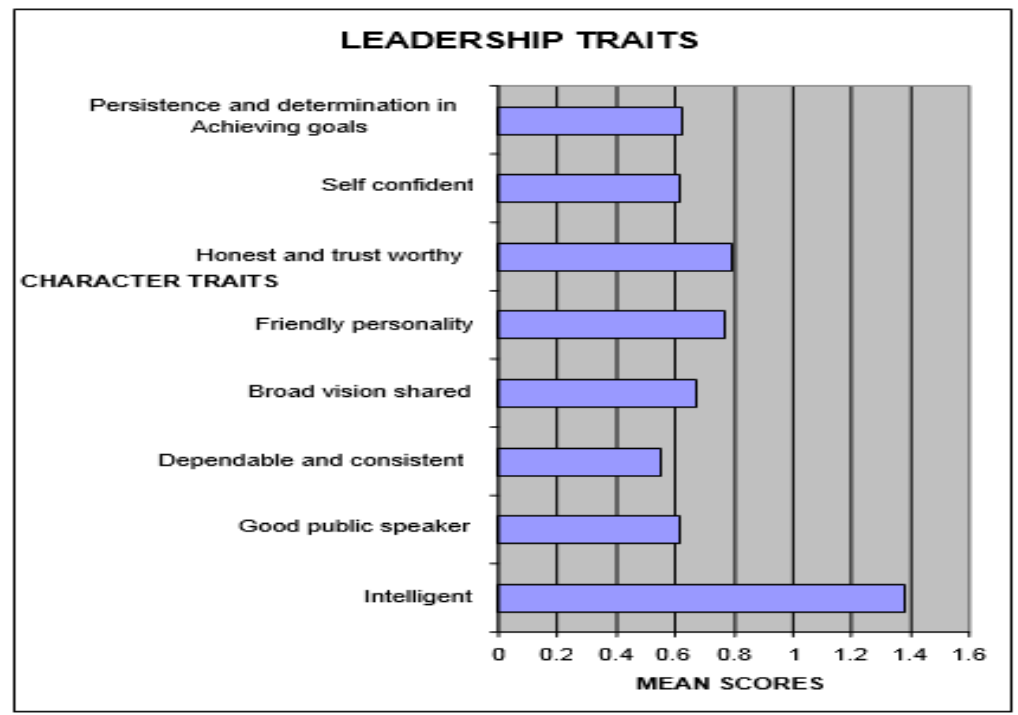

Graph \# I: Perception of teachers about character traits of good leaders 
Table \# 11: Percentage response about behavior of good leaders

\begin{tabular}{lcccc}
\hline Behaviors & Choice I & Choice II & Choice III & Mean Value \\
\hline attend to our well being \& human needs & 20.0 & 9.0 & 5.0 & .83 \\
Appealed to out higher moral values & 13.0 & 10.0 & 9.0 & .68 \\
worked with us as a team & 23.0 & 16.0 & 11.0 & 1.12 \\
gave clear instructions & 7.0 & 8.0 & 14.0 & .51 \\
treated us with respect & 19.0 & 21.0 & 15.0 & 1.14 \\
invited us to share in decision making & 10.0 & 13.0 & 12.0 & .68 \\
Improve social relationships & 2.0 & 7.0 & 19.0 & .39 \\
challenged us to perform at our highest possible & 6.0 & 16.0 & 15.0 & .65 \\
\hline
\end{tabular}

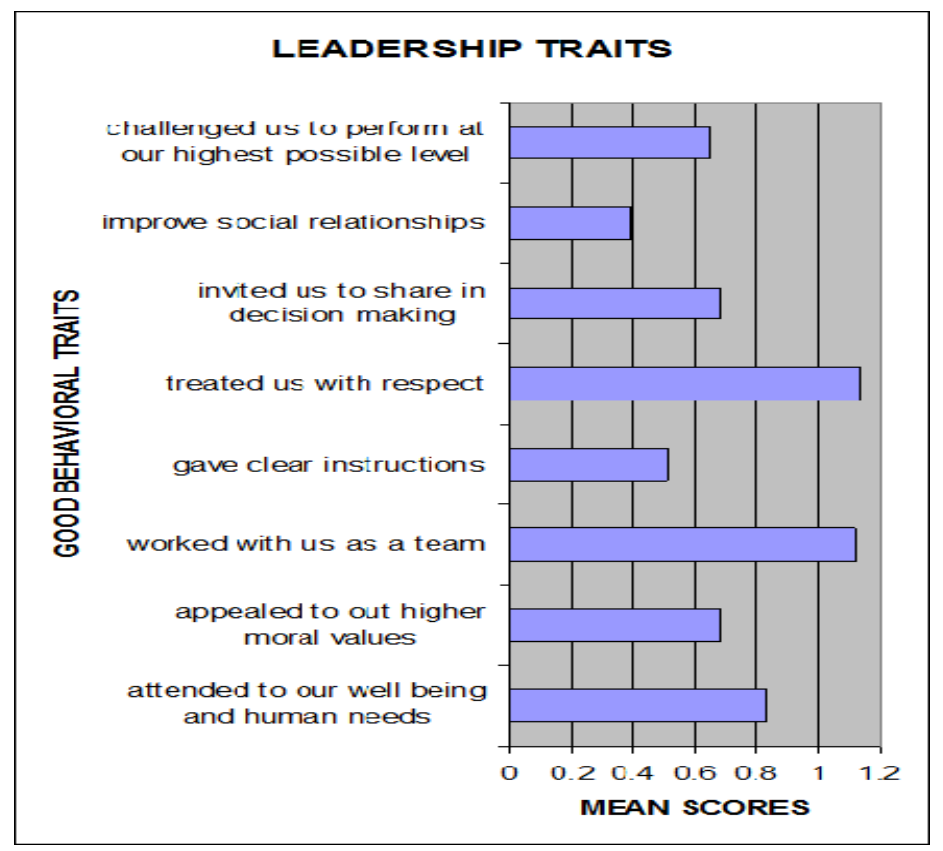

Graph \# II: Perception of teachers about behavior of good leaders

Table \# 1Il: Percentage response about character traits of bad leaders

\begin{tabular}{lcccc}
\hline Character traits & Choice I & Choice II & Choice III & Mean Value \\
\hline Stupid & 39.0 & 5.0 & 4.0 & 1.31 \\
could not express well & 15.0 & 10.0 & 8.0 & .73 \\
say one thing and do opposite & 13.0 & 15.0 & 6.0 & .75 \\
narrow minded & 8.0 & 27.0 & 14.0 & .92 \\
unfriendly personality & 1.0 & 8.0 & 13.0 & .32 \\
dishonest and deceitful & 14.0 & 17.0 & 18.0 & .94 \\
not confident in achieving tasks & 3.0 & 8.0 & 15.0 & .40 \\
did not have strong will to succeed & 5 & 8.0 & 20.0 & .51 \\
\hline
\end{tabular}




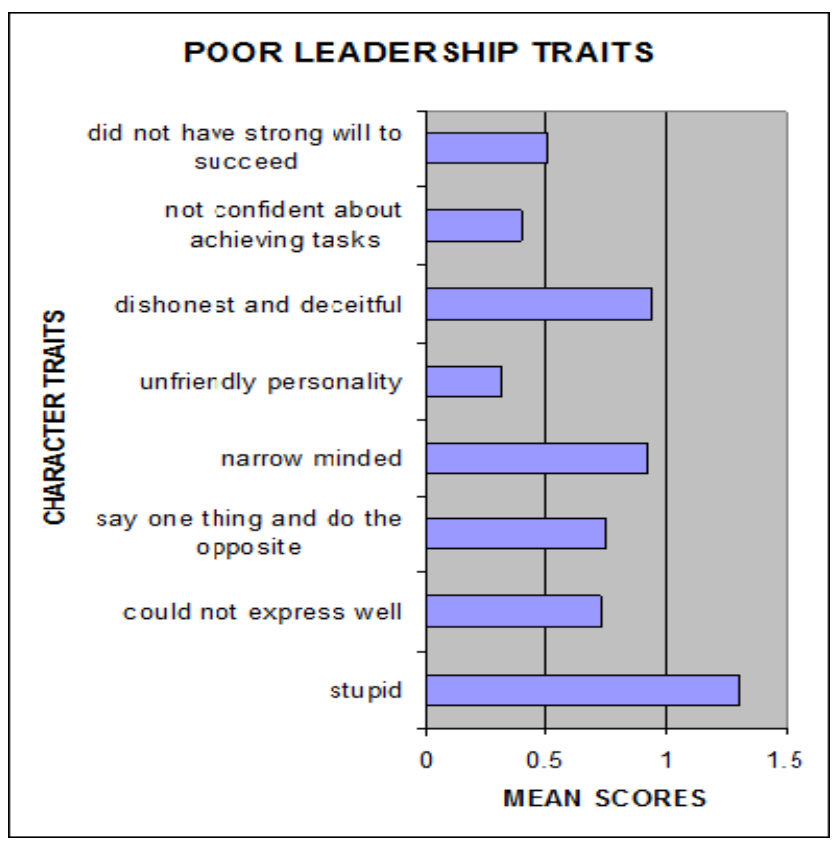

Graph \# III: Perception of teachers about character traits of bad leaders

Table \# 1V: Percentage response about behavior of bad leaders

\begin{tabular}{lcccc}
\hline Behaviors & Choice I & Choice II & Choice III & Mean Value \\
\hline interested in her own promotion & 28.0 & 12.0 & 13.0 & 1.21 \\
Appealed to our selfishness & 16.0 & 9.0 & 4.0 & .70 \\
no sense of team work & 17.0 & 16.0 & 14.0 & .97 \\
did not make clear what wanted to do & 3.0 & 8.0 & 10.0 & .35 \\
treated us like naughty children & 3.0 & 15.0 & 12.0 & .51 \\
acted like a dictator & 18.0 & 17.0 & 15.0 & 1.03 \\
feared criticism and opposition & 5.0 & 11.0 & 16.0 & .53 \\
engaged in corruption and nepotism & 8.0 & 10.0 & 14.0 & .58 \\
\hline
\end{tabular}




\section{LEADERSHIP TRAITS}

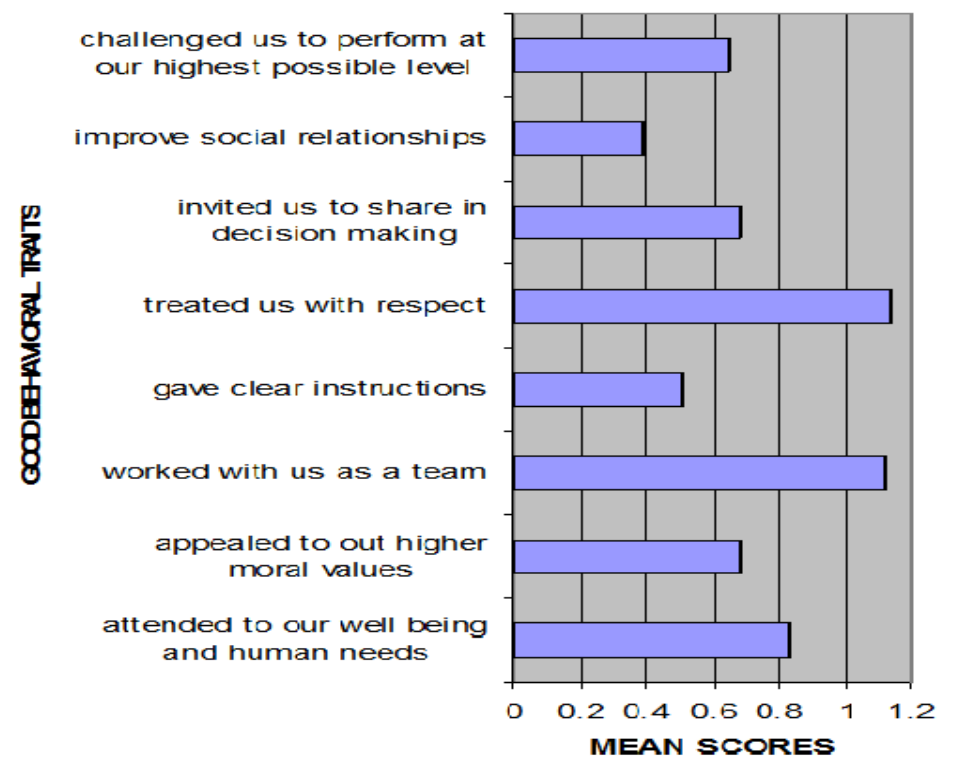

Graph \# IV: Perception of teachers about behavior of bad leaders

\section{Discussion}

The following tables summarize the mean values for the various categories:

\section{Character Traits of Good Leaders}

\begin{tabular}{lclclc}
\hline Traits & Mean scores & Traits & Mean scores & Traits & Mean scores \\
\hline Intelligent & 1.38 & Public speaker & .61 & Consistent & .55 \\
Broad vision & .67 & Friendly & .77 & Honesty & .79 \\
Self confident & .61 & Persistence & .62 & & \\
\hline
\end{tabular}

The Pakistani teachers were quite clear in their assessments about good leadership traits. The most important trait that they want to see in their leaders is intelligence, with a mean value of 1.38 , which greatly surpassed other mean scores, while the second choice was being honest and trustworthy. Having a friendly personality with broad vision was taken as the third highest quality for a good leader. The least important trait for a good leader is being self confident and persistent.

\section{Behaviors of Good Leaders}

\begin{tabular}{lclccc}
\hline Traits & Mean scores & Traits & Mean scores & Traits & Mean scores \\
\hline Well being & .83 & Moral values & .68 & Team work & 1.12 \\
Clear instruction & .51 & Others respect & 1.14 & Democratic & .68 \\
Social & .39 & Challenged & .65 & & \\
\hline
\end{tabular}

In Pakistani educational situations, people usually want their leaders to treat them with respect and dignity and work with them as a team. On a second stage of preference they would like their leaders to care for them and attend to their well 
being thoroughly. Thirdly people like their leaders to appeal to high moral values. It is very important to note that people think sociability as the least important trait for an educational leader.

\section{Character Traits of Bad Leaders}

\begin{tabular}{lclclc}
\hline Traits & Mean scores & Traits & Mean scores & Traits & Mean scores \\
\hline Stupid & 1.31 & No expression & .73 & Say/do opposite & .75 \\
Narrow mind & .92 & Unfriendly & .32 & Dishonest & .94 \\
Not confident & .40 & Weak will & .51 & & \\
\hline
\end{tabular}

In the same manner, traits of bad leaders were also evaluated. It is evident that being stupid is the worst thing for a leader to be recognized as a bad one. Being dishonest and narrow minded are rated almost equally as second highest traits of bad leaders. Contradiction between sayings and actions was ranked as the fourth most important consideration in the perception of bad leaders. Being unfriendly was given least importance in the evaluation of bad leaders by college/school teachers.

\section{Traits of bad leader (behavioral)}

\begin{tabular}{lclclc}
\hline Traits & Mean scores & Traits & Mean scores & Traits & Mean scores \\
\hline Self promotion & 1.21 & Selfishness & .70 & No teamwork & .97 \\
Not clear & .35 & Treat naughty & .51 & Dictator & 1.03 \\
Feared criticism & .53 & corrupted & .58 & & \\
\hline
\end{tabular}

Pakistani teachers gave highly negative ratings to leaders who are much more interested in their own self promotion and selfish goals, and those who act like dictators. Having no spirit of team work was rated as third most unfavorable trait for a leader to be perceived as a bad one. At the fourth highest level, a leader who appeals to our selfishness is also taken as a bad leader. Here it is important to note that not to give right instructions is a bad trait but may be excused as compared to other evils.

\section{Summary}

In summary, the following are the first, second, and third ranked choices for each group:

\section{Traits of Good Leaders}

$\begin{array}{ll}\text { First } & \text { intelligence } \\ \text { Second } & \text { honest and trust worthy } \\ \text { Third } & \text { friendly personality }\end{array}$

Traits of Bad Leaders

First

Second

Third

\section{Behavior of Good Leaders}

First

Second

Third

\section{Behavior of Bad Leaders}

First

Second

Third stupid

narrow minded and dishonest

contradictory in saying and doing

team work and treat with respect

well being

shared decision making and moral values

self promotion and dictator

no team work

appeal to selfishness 
Thus the trait that is taken as most crucial for our society's educational leaders is intelligence which appears on the top of all good qualities and at the same time stupidity appears on the top of bad leadership traits. Then being honest is rated as the second highest quality in good leadership traits and also considered at second level as dishonesty in bad leadership traits. Being friendly is thought as third important trait in the evaluation of good leaders whereas hypocrisy (say one thing and do something else) is taken as the third important trait to consider a leader as a bad one. If a leader is working as a team with his subordinates while treating them with respect and honor, he is thought of as a good leader. On the other hand, if a leader is interested in his own selfish aims and self promotional activities, he is thought of as bad leader. To take care to team members' well being is the second highest quality for a leader and to have no team spirit is ranked as a second bad trait of a leader for a poor leadership. If a leader shares his/her views with his colleagues while making decisions and encourages them to have high moral standards, he/she is also thought as a good leader at the third highest level. At the same time, if he/ she appeals to his/her colleagues selfishness, this trait of a leader is taken as a poor leadership trait. As these two qualities could not be present at the same time in one person, it is well understood that they support each other logically and empirically.

\section{Recommendation:}

According to Hofstede's (1993) management is viewed differently in different cultures. Likewise, recent research (Zepp and Khalid, 2009) has shown that perceptions of good and bad leadership vary greatly from culture to culture. It is therefore recommended to judge the verification of results on other similar cultures in the country and in other south Asian countries for validity, reliability and generalizability purposes.

\section{References}

Adair,J. (1973). The Action-Centred Leader. McGraw-Hills, London.

Bottery ,M.(1994) Lessons for schools? London: Cassell.

Bowers, D \& Seashore, S. (1966), "Predicting organizational effectiveness with a four-factor theory of leadership", Administrative Science Quarterly, vol. 11, pp. 238-63.

Christie, P. and B. Lingard (2001) "Capturing complexity in educational leadership", American Educational Research Association, ERIC document ED461930.

Fielder, F. (1967) A Theory of Leadership effectiveness, (New York), McGraw Hill.

Fremont E. Kast and James E. Rosenzweig.(1986) 4th ed., Organization and Management: A system and contingency approach. New York: McGraw-Hill Book Company. 359 -389

Gunter, H.(2001). Leaders and leadership in Education. London: Paul Chapman.

Hofstede, G. (1993). "Cultural constraints in management theories". Academy of Management Executives. Feb. 1993, p. 91.

Keith Davis 1977. Human Behavior at Work., 5th ed., New York: McGraw-Hill Book Company.

Kotter, J. P. (1991). Power, dependence and effective management, in managing people and organizations. Boston, MA: Harvard Business School Publications.

Martin Thrupp and Robert Willmott. (2003). Education management in managerialist times. Beyond the textual apologies. Philadelphia : Open University Press. pp. 142-181.

Michael Armstrong and Tina Stephens.(2006). A handbook of management and leadership: A guide to managing for results. London: Kogan Page limited. p.16.

Okure, S.J., (2004). "The most appropriate leadership style of the school principal in a school system". West Arican Journal of Research and Development, vol 11, no. 13, 2004.

Sergiovanni, T.J. (2001b). Leadership: What is in it for schools? London: Routledge Falmer.

Stephen R.Covey. (1997). Principle-Centered Leadership. London: Simon \& Schuster Ltd.

Stodgill, R. M. and Corms A. E. (ed.), (1951). Research Monograph no. 88 (Columbus, Ohio State university Bureau of Business Research).

Solomon Ben. (1950). Leadership of Youth, New York: Youth Services. p.15.

Tom Barker. (2007). Leadership for Results. India : Taj Press.

Zaleznik, A (2004). Manager and leaders: are they different?Harvard Business Review. January.

Zepp, R, and Mona, A. (2009). Teachers' Perceptions of Good and Bad Leaders in Seven Cultures. Academic Leadership Journal, vol. 7, Feb. 23, 2009. ISSN 1533-7812. 